\title{
CLINICAL AND EPIDEMIOLOGICAL FEATURES OF CHILDREN WITH SEVERE INFLUENZA ADMITTED TO PEDIATRIC INTENSIVE CARE UNIT IN GREECE DURING 2009-2018
}

\section{espoic}

Kazantzi Maria, Christakou Eleni, Prapa Marilena, Tsirogianni Chrysanthi, Staurou Vasillios,

Kalampalikis Panagiotis, Paraschou Dimitra, Barbaresou Chariklia.

Pediatric Intensive Care Unit, Aghia Sophia Children's Hospital, Athens, Greece.

\section{BACKGROUND-AIM}

Influenza is a viral disease that is often associated with respiratory failure and other severe complications. The aim of this study was to outline the incidence, clinical characteristics, and outcomes in critically ill children with influenza admitted to a pediatric intensive care unit (PICU) during nine years.

\section{METHODS}

Retrospective study conducted in the main PICU in Greece. All patients with confirmed influenza infection, detected by reverse-transcriptase polymerase chain reaction assay, between September 2009 and April 2018 were included.

\begin{tabular}{|c|c|c|}
\hline \multicolumn{2}{|c|}{ Characteristics } & \\
\hline \multicolumn{2}{|l|}{ Sex, male } & $15(53,6)$ \\
\hline \multicolumn{2}{|c|}{ Age, years } & $5(0,5-12)$ \\
\hline \multicolumn{2}{|c|}{$\begin{array}{l}\text { Underlying medical } \\
\text { condition }\end{array}$} & $14(50)$ \\
\hline \multicolumn{3}{|c|}{ Body Mass Index } \\
\hline & Normal & $22(78,6)$ \\
\hline & Overweight & $3(10,7)$ \\
\hline & Obese & $3(10,7)$ \\
\hline \multicolumn{3}{|c|}{ Cause of admission } \\
\hline & Respiratory distress or failure & $12(43)$ \\
\hline & Bacterial superinfection & $11(39,3)$ \\
\hline & Other & $5(17,8)$ \\
\hline \multicolumn{2}{|c|}{$\begin{array}{l}\text { Interval between symptoms onset and admission to } \\
\text { hospital, days }\end{array}$} & $3(2-5)$ \\
\hline \multicolumn{2}{|c|}{$\begin{array}{l}\text { Interval between symptoms onset and admission to } \\
\text { PICU, days }\end{array}$} & $4(2-10)$ \\
\hline \multicolumn{3}{|c|}{ Infection origin } \\
\hline & Community & $24(85,7)$ \\
\hline & Nosocomial & $4(14,3)$ \\
\hline \multicolumn{3}{|c|}{ Type of influenza virus } \\
\hline & H1N1 & $18(64,3)$ \\
\hline & H3N2 & $1(3,6)$ \\
\hline & B & $9(32,1)$ \\
\hline \multicolumn{2}{|c|}{ Mechanical ventilation } & $20(71,4)$ \\
\hline \multicolumn{2}{|c|}{ Days of mechanical ventilation } & $7(1-13)$ \\
\hline \multicolumn{2}{|l|}{ Shock } & $9(32,1)$ \\
\hline \multicolumn{2}{|c|}{ Length of PICU stay days } & $8(5-28)$ \\
\hline \multicolumn{2}{|c|}{$\begin{array}{l}\text { Interval between symptoms onset and commencement } \\
\text { of antiviral treatment, days }\end{array}$} & $4(2-7)$ \\
\hline \multicolumn{2}{|c|}{ Outcome, death } & $10(35,7)$ \\
\hline
\end{tabular}

\section{CONCLUSIONS}

$>$ Influenza and its complications are a cause of PICU admission.

$>$ It is often related to adverse outcome especially among children with underlying chronic conditions.

$>$ Pandemic subtype A H1N1 was associated with severe disease in season 2015-2016

$>$ The 2017-2018 season was dominated by influenza B virus. H3N2 case.

\section{RESULTS}

-A total of 28 patients with confirmed influenza required critical care.

-The majority of patients(15/28, 53,6\%), were admitted in season 2015-2016, in which the predominant influenza virus was AH1N1 $(10 / 15,66,7 \%)$.

-The prevailing strain in season 2017-2018 is Influenza B (4/5) with an exception of one

-None of the patients had been vaccinated for influenza.

- 14 (50\%) children had an underlying chronic illness.

- Cause of admission to PICU was respiratory failure $(12 / 28,43 \%)$, bacterial co-infection $(11 / 28,39,3 \%)$, thrombotic thrombocytopenic purpura $(1 / 28)$, hemophagocytic syndrome(1/28), capillary leak syndrome $(1 / 28)$,encephalitis $(1 / 28) \mathrm{kal}$ myocarditis/pericarditis(2/28).

-The mortality rate for the period of 20152016 was 53\% (8 patients) compared to an overall mortality rate of $35,7 \%$ (10 patients). -2 patients $(11,1 \%)$ had residual problems after discharge.

-The death rate was significantly higher among children with underlying chronic disease versus previously healthy children ( $8 / 14$ vs $2 / 14$, $\mathrm{p}: 0.018)$. 